\title{
TESTING THE EFFECTS OF EXPERIMENTAL SNOW Removal on SoIL MoIsture and Plant Responses in Montane MeAdows
}
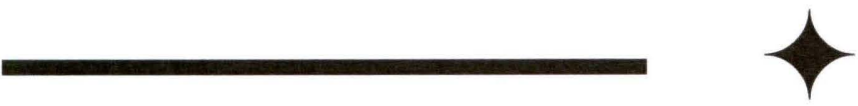

\section{DiANE M. DEBINSKI DEPARTMENT OF ECOLOGY, EVOLUTION AND ORGANiSMAL BIOLOGY IOWA STATE UNIVERSITY $\downarrow$ AMES}

\author{
MATTHEW GERMINO \& DENNIS DEMSHAR $\uparrow$ DEPARTMENT OF BIOLOGY \\ IDAHO STATE UNIVERSITY $\downarrow$ POCATELLO
}

\begin{abstract}
$\uparrow \quad$ ABSTRACT
Regional models of global climate change for the northern Rocky Mountains predict warmer temperatures and western states have shown a recent trend towards increases in the fraction of precipitation falling as rain rather than snow. Thus, the amount of soil moisture available to plants during the growing season may already be varying significantly from historical conditions. In order to simulate drier summer soil conditions and test soil moisture and plant responses, we set up a pilot snow removal experiment in Grand Teton National Park, WY in 2008. Because most of the precipitation comes in the form of snow, and spring snowpack is about $50 \%$ water by volume, removing all snow present in early May can reduce the annual precipitation by approximately half. Snow was removed from three $\sim 9 \times 15$ m experimental plots using a Thiokol in early May. These experimental sites were paired with adjacent control sites and the pairs were established along a hydrological gradient of meadow types representing hydric, mesic, and xeric sites. Dataloggers were installed in June and soil moisture was monitored at 5, 20, and $50 \mathrm{~cm}$ depths through August. Water potential was measured in Bromus and Carex during mid-July. Over the summer season, there were differences in soil water between the snow removal and control plots, as well as across the hydrological gradient. Decreases in soil water content and water potential of Carex showed strongest responses in the mesic site, whereas Bromus showed the strongest response in the hydric site. This is the first
\end{abstract}

study to reveal that variability in spring snowpack can lead to measurable impacts on the vegetation community, even into mid-late summer when soil water is fairly scarce throughout the landscape. Furthermore, changes in snow depth are not likely to have equivalent impacts on the different community types within a region; the effects will vary predictably as a function of soil and plant community characteristics.

\section{$\uparrow \quad$ INTRODUCTION}

In semi-arid, continental regions such as the Greater Yellowstone Ecosystem (GYE) one of the most important questions relative to climate change may be how the variation in soil moisture (both seasonally, and throughout the soil profile) affects different functional groups of plants and how these changes are manifested in the ecological community at large. Regional models of global climate change for the northern Rocky Mountains predict warmer temperatures (Reiners et al. 2003) and western states have shown a recent trend towards increases in the fraction of precipitation falling as rain rather than snow (Mote et al. 2005; Knowles et al. 2006). The summers of 2000-2007 were characterized by much higher drought conditions relative to average summer months from 1885-1996 based upon monthly Palmer Drought Severity Index values (Debinski et al., unpublished data). Thus, the amount of soil moisture available to plants during the growing season may already be varying significantly from historical conditions. 
Montane meadows can provide an early warning system for how plant communities in the GYE are responding to climate change. They exist in a predominantly arid matrix and are arrayed along a unique hydrological gradient (from hydric to mesic to xeric) with their boundaries defined by soil type, soil moisture, herbivory, and fire (Despain 1990). They are vegetated by grasses, shrubs, sedges, and forbs, allowing for quick responses to changes in precipitation and temperature. Because the landscape of the Greater Yellowstone Ecosystem is composed of such a broad mosaic of these meadows, it provides an opportunity to examine landscape-level responses to climate change. Each of these meadow types has a different soil type, soil profile, and ability to hold moisture. Therefore, changes in precipitation may be differentially manifested across the meadow types depending upon this soil type. In some meadows, additional precipitation may make no difference if the soil has little ability to hold that moisture. The movement and storage of moisture within the soil profile will be affected by the position of the meadow along the hydrological gradient.

Increasing soil and air temperatures, and altered precipitation patterns will have effects on the physiological processes and competitive relationships among vascular plants in this relatively xeric environment (Ehleringer et al. 2000), and these effects could have significant repercussions through the system affecting higher trophic levels. Relative abundances of plant functional groups could change because shallower-rooted plant species utilize intermittently available water from summer rains, whereas deeperrooted species rely more on precipitation stored in deep soils during snowmelt (Dodd et al. 1998; Williams and Ehleringer 2000). The relative percent cover of forbs, shrubs, and bare ground in low elevation meadows has shown changes over the past decade. Forbs, which are generally more shallow-rooted, have been decreasing whereas shrubs such as sagebrush (Artemisia spp.), which are deeper-rooted, are increasing (Debinski et al., unpublished data).

There is a need for experimental data that will allow us to understand how changing precipitation and dates of snowmelt may affect ecological communities. In other ecosystems, rainout, rain addition structures, or warming lights have been utilized to modify the amount of precipitation or the temperature of a grassland site (Germino and Smith 1999, Cross and Harte 2007). However, because our study sites are located within Grand Teton National Park, we wanted to minimize the visible structures associated with our experiment. We worked with Park Service research staff members to construct an approach that was minimally invasive but also allowed us to test these hypotheses in a rigorous fashion. The solution involved manipulating the amount of snow on the ground in May. Assuming that these sites get about $53 \mathrm{~cm} / \mathrm{yr}$ of precipitation (Shaw, 1958), mostly as snow, and that spring snowpack is about $50 \%$ water by volume (http://cdec.water.ca.gov/snow/misc/density.html), then removing $50 \mathrm{~cm}$ of the snowpack (i.e., all snow still present in early May) could reduce the annual precipitation by half. Snow was removed using a "Thiokol" tractor with tank-like treads such that the soil and vegetation disturbance is minimized. Use of such machinery allowed for the creation of much larger experimental plots compared to some of the plots associated with rainfall exclosures.

The central hypothesis for this research was that soil moisture is a major environmental driver in this ecosystem, and that if soil moisture changes, changes in the ecological community will be differentially manifested as a function of their position on the hydrological gradient. More specifically, we expected that snow removal in May would reduce soil moisture in experimental relative to control plots. Differences would be exhibited primarily at the shallow $(5 \mathrm{~cm})$ and intermediate depths $(25 \mathrm{~cm})$ and less so in the deepest depths $(50 \mathrm{~cm})$. We expected that the intermediate depth $(25 \mathrm{~cm})$ would show the longest temporal effects. We also expected that the difference in soil moisture between experimental and control plots would be maintained though a portion of the summer growing season, but would dissipate by August.

Whether changes in precipitation affect shallow or deeper soil water could have major repercussions on the balances of herbaceous versus woody species. Our rationale for predicting the 20-50 $\mathrm{cm}$ depths to have the most important change in water availability is based on our previous observations that meadow soils at $\sim 20$ to $50 \mathrm{~cm}$ depth tended to become very dry by mid-late summer, regardless of annual precipitation patterns (to near $-5 \mathrm{MPa}$ or $<10 \%$ Volumetric Water Content (VWC); values below the extraction limit of the plant community; from the years 2000-2005, Hill et al. 2006; Inouye 2006). In contrast, soils below about $100 \mathrm{~cm}$ depth tend to more reliably have water available to the fewer roots present at these deeper depths, even during drought years (the exact depth varies by soil and vegetation type). Thus, in contrast to Walter's (1971) bi-layer model of soil resources, we envisioned three key horizons in soil: i) a shallow layer $(\sim<20 \mathrm{~cm})$, which tends to dry below levels useful to plants in nearly every growth season, but a layer that may intermittently have small amounts 
of wetting from summer rains, ii) a mid-layer $(\sim 20-50$ $\mathrm{cm}$ ) in which most plant species will have at least some roots, and a layer in which the availability of soil water can vary substantially among years, and iii) a deep layer $(\sim 50-100 \mathrm{~cm})$ that more reliably has available soil water owing to limited rooting and only in certain species.

\section{$+\quad$ MeTHODS}

\section{Plot selection and establishment}

Three sites were selected for a pilot test of snow removal in 2008 at the University of WyomingNational Park Service Research Station in Moran, WY (Fig. 1). Snow removal sites were approximately $15 \times 9$ $\mathrm{m}$ in size. These included a xeric site (Site 1, Lawrence House), a mesic site (Site 2, Boise Barn) and a hydric site (Site 3, Berol Lodge). All three sites were flat and relatively homogeneous in vegetation composition. Within the snow removal area, a $5 \times 10 \mathrm{~m}$ plot was established which was at least $2 \mathrm{~m}$ from the edge of the snow removal area. An adjacent "control" site, also $5 \mathrm{x}$ $10 \mathrm{~m}$ in size, was located a minimum of $2 \mathrm{~m}$ away. The distance between control and experimental plots was selected so that we could minimize edge effects but also place them close enough so that a datalogger could be positioned in the middle and linked via cables to both the experimental snow removal and the control plots.

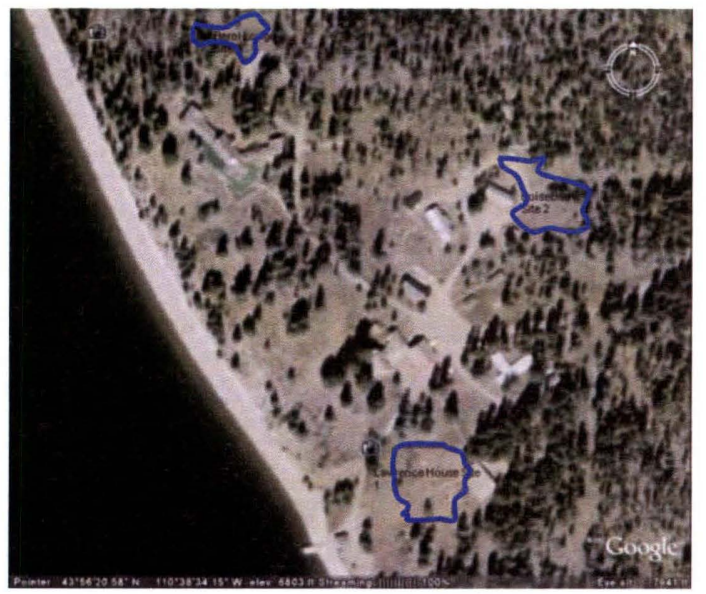

Fig. 1. Location of three sites for snow removal experiment in 2008 from Google Earth, June, 2008 http://earth.google.com/. Each site included a snow removal plot and a control plot. Research was conducted on the premises of the University of Wyoming National Park Research Station Moran WY

\section{Snow removal}

Snow was removed on May 10, 2008, when there was about $83 \mathrm{~cm}$ of snow on the ground (equivalent to $\sim 41 \mathrm{~cm}$ of water). The Thiokol has a tank-like tread and was driven in a linear fashion, removing snow layer by layer, a few inches at a time, starting at the top layer and moving down toward the soil. Snow removal stopped when soil became just barely visible, minimizing the effects of tracking on the plot. Figures 2 and 3 show images of Site 2 at the time of snow removal and one week post snow removal.

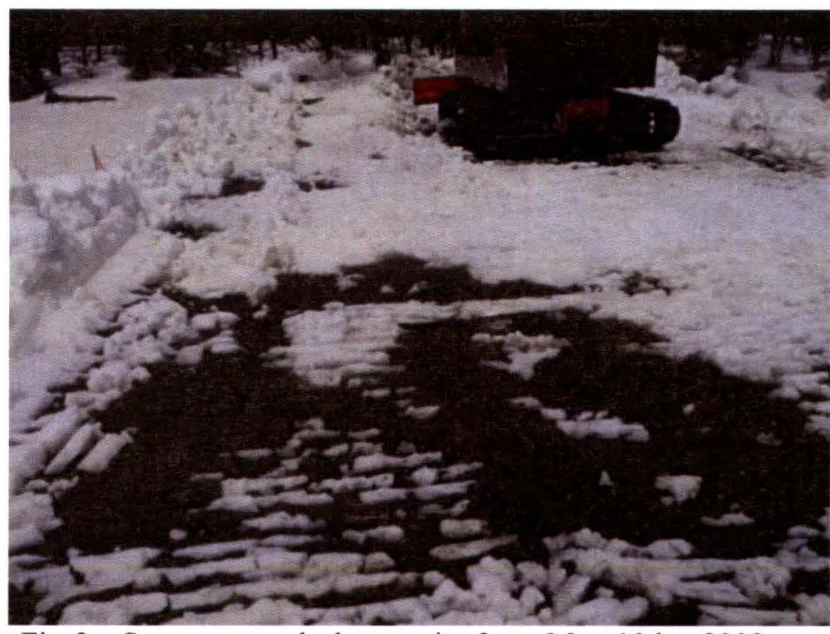

Fig 2. Snow removal plot on site 2 on May 10th , 2008. Thiokol used for snow removal in background. Photo by Rich Viola.

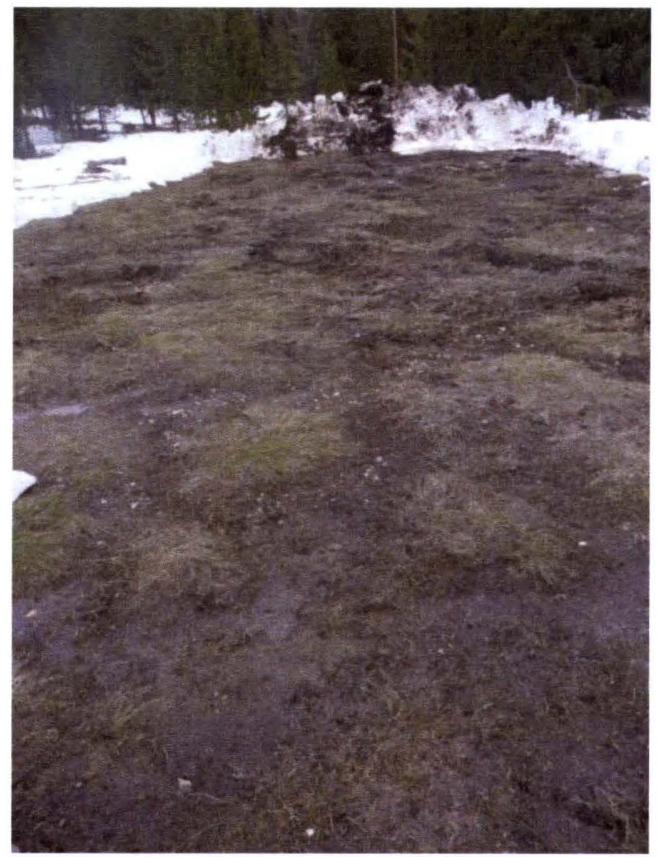

Fig 3. Snow removal plot on site 2, May 17th, 2008. Photo by Rich Viola.

\section{Soil Moisture Data}

Datalogger installation occurred during the last snowfall in early June (one per experimental and one per control at each site, $n=6$ sites monitored), and 
within a few days a strong trend of seasonal drying occurred through midsummer. Volumetric Water Content (VWC; $\mathrm{m} 3 / \mathrm{m} 3$ ) was assessed in experimental plots during the snow-free season using daily data logger recordings (CR10, Campbell Scientific, Logan UT) of dielectric soil water content sensors (ECHO 5 $\mathrm{cm}$ probes, Decagon Inc, WA) positioned at 5,25 , and $50 \mathrm{~cm}$ deep in soil. Datalogger function varied among plots. Sites 1 and 2 provided data throughout several weeks of the summer season. However, very little data was obtained from Site 3 .

\section{Vegetation Water Content}

Bromus inermis and Carex leptalea Wahl were used to assess water potential of the plant community within each of the plots because they were relatively common in each of the plots. Three individuals of each species were collected before dawn from each of the six plots and their plant water potential was determined within minutes of harvest using a pressure chamber (PMS, Corvallis OR). Averages were calculated for each site so that comparisons could be made between experimental and control plots.

\section{$\uparrow \quad$ RESUltS AND DiscuSSION}

There were detectable differences in soil water among the snow removal and control plots throughout the summer growing season, and differences were also evident among the three sites. One month following snow removal, the strongest differences across all sites occurred at the mid-depth of $25 \mathrm{~cm}$. (Fig. 4). These differences were also maintained throughout the summer season. Data from Site 2 (mesic site) at $25 \mathrm{~m}$ depth are provided as an example (Fig. 5). However, responses varied with soil depth and exhibited a temporal component. At both Sites 1 and 2, the $5 \mathrm{~m}$ depth was most strongly affected by snow removal early in the season (Fig. 6). However, the mid-depth $(25 \mathrm{~cm})$ response to snow removal was more sustained throughout the season than the response at the $5 \mathrm{~cm}$ depth in Site 2 (mesic site). As we had hypothesized, this strong response at $25 \mathrm{~cm}$ creates the potential for strongest effects on plant species that rely most on the mid depth soil moisture (grasses in midsummer drought). The $50 \mathrm{~cm}$ depth exhibited a mildly inverse response to snow removal at both sites, becoming more depleted in soil water later over the growing season at Site 2. This inverse response could have resulted from vigorous plant growth in the control plot early in the season tapping that deeper soil moisture later in the summer at the onset of seasonal drought.

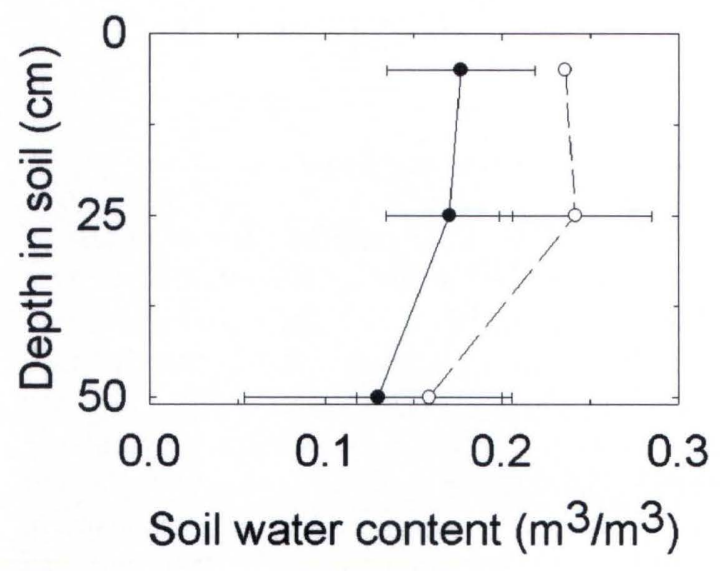

Fig. 4. Variation in soil water content one month following removal of spring snowpack (closed symbols) and adjacent control plots (open symbols). Data are from $n=3$ meadows, collected over 2 days using Decagon Echo Probes. Soils were coarse textured, with field capacity near $23 \%$ on a volumetric basis.

Table 1 shows that both the Carex and Bromus species showed water potential differences generally in the direction expected, and Carex showed the strongest response to snow removal in the mesic site. Bromus showed the strongest response in Site 3 (hydric site) but also showed an inverse response in Site 1 (xeric site). This inverse relationship may be explained by the way the spring rains pooled differentially across the gradient in snow removal plots before the surrounding snow had melted (Viola pers. comm.). This pooling did not occur in the other sites. It is possible that the soil in Site 1 (the xeric site) is underlain by a clay layer that slowed the process of infiltration. Soil moisture data showed that the snow removal effect was least evident at Site 1, exhibited inverse responses at $50 \mathrm{~cm}$ depth, and mainly occurred during the first few weeks that the datalogger was installed. In Sites 2 and 3, differences in soil water content and plant water potential were more evident and lasted throughout the summer season. 


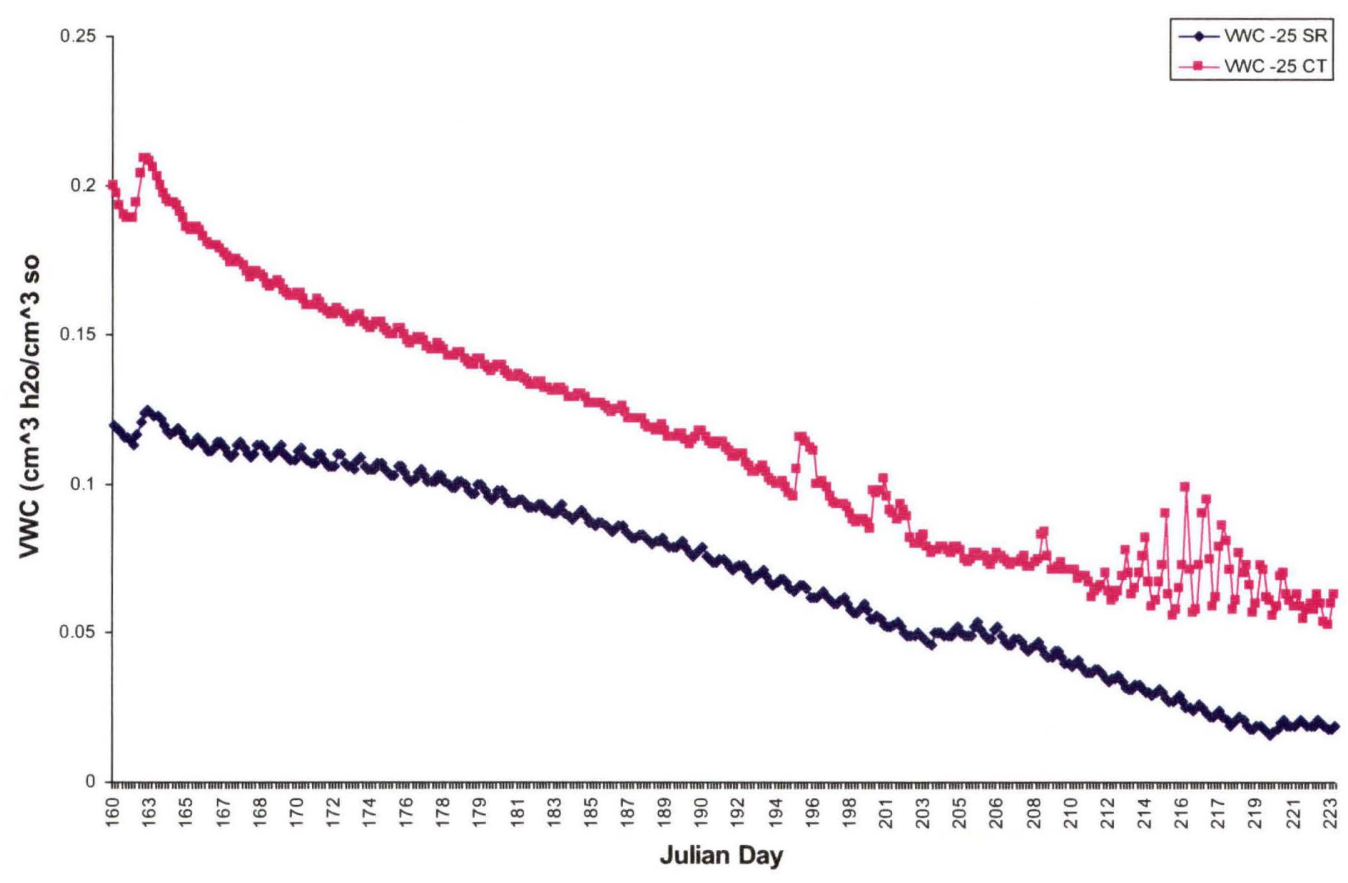

Fig. 5. Variation in volumetric soil water content from Julian Day 160 (June 8, 2008) through Julian Day 233 (August 10, 2008) in snow removal (SR) and adjacent control treatment plots (CT). Data are from Site 2 (mesic site) at $25 \mathrm{~cm}$ depth.

\begin{tabular}{lllll}
\hline & \multicolumn{1}{l}{$\begin{array}{l}\text { Mean } \\
\text { MPa }\end{array}$} & s.e. & CTRL-SR & \% difference \\
\cline { 2 - 5 } Brome & & & & \\
site 1 ctrl & -3.45 & 0 & -1.08 & -31.16 \\
site 1 SR & -2.38 & 0.3 & & \\
site 2 ctrl & -0.84 & 0.2 & 0.37 & 43.71 \\
site 2 SR & -1.20 & 0.4 & & \\
site 3 ctrl & -0.76 & 0.1 & 0.38 & 50.11 \\
site 3 SR & -1.13 & 0.1 & & \\
Carex & & & & \\
site 1 ctrl & -3.01 & 0.4 & -0.06 & -1.99 \\
site 1 SR & -2.95 & 1.2 & & \\
site 2 ctrl & -0.77 & 0.6 & 0.51 & 65.95 \\
site 2 SR & -1.28 & 0.8 & & \\
site 3 ctrl & -0.64 & 0.2 & 0.01 & 1.56 \\
site 3 SR & -0.65 & 0.1 & & \\
\hline
\end{tabular}

Table 1. Mean, standard error, and percent difference for water potential for Brome and Carex samples from control (CTRL) and experimental (SR) plots based upon three replicates per sampling plot for each gramioid.

\section{$\downarrow \quad$ CONCLUSIONS}

Our data provide preliminary evidence that in systems where snow is a major constituent of the total precipitation, snow manipulation offers an efficient way to adjust the annual water balance and can provide a compelling analog to climate change projections. Responses varied with depth in the soil profile and with position along the hydrological gradient. We found that the meadow in the middle of the hydrological gradient (Site 2) was the most strongly affected by the snow removal and for that meadow type the mid-depth $(25 \mathrm{~cm})$ of soil was the zone that exhibited most significant and lasting change in response to snowpack manipulation. We hypothesize that these differential responses occur because extremely dry sites are composed of such shallow soil that changes in the soil moisture have minimal lingering effects. Conversely, wetter sites are not as significantly affected by changes in soil moisture because they have more of a "buffer" of water availability. Sites in the middle of the moisture gradient are probably most vulnerable to small changes in precipitation. 

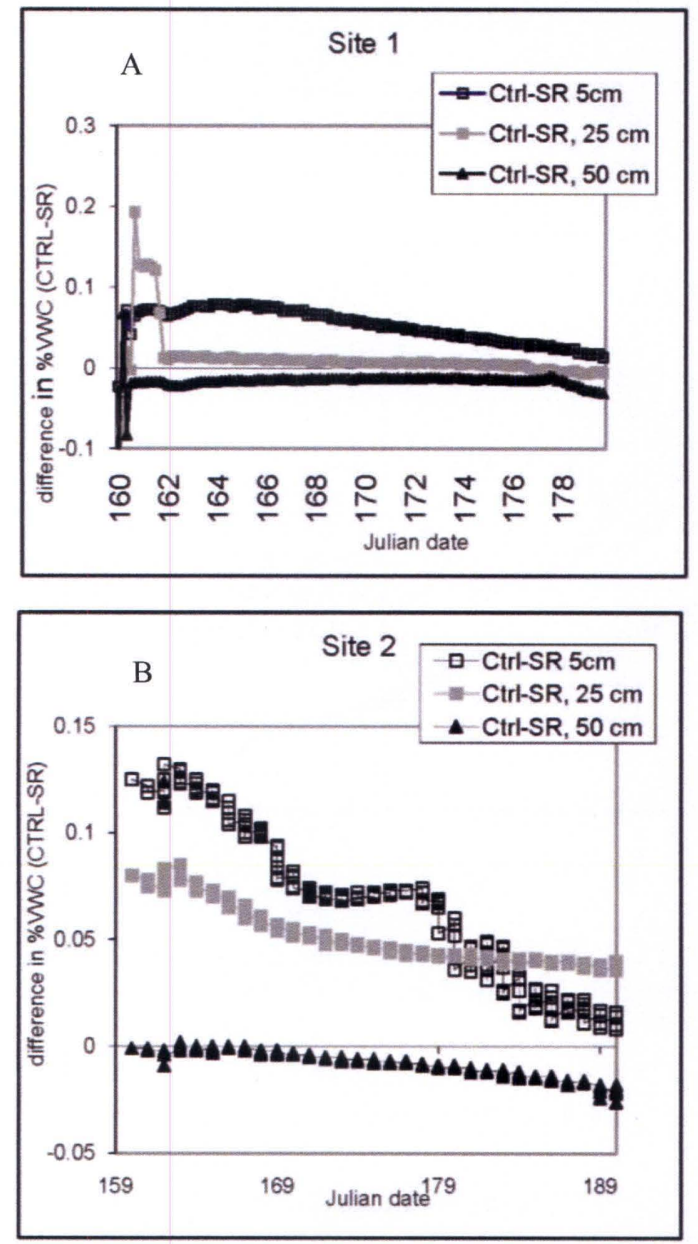

Figure $6 \mathrm{~A}$ and B. Difference in Volumetric Water Content (VWC) of soil at three depths between control and experimental plots in sites 1 (xeric) and 2 (mesic) over the summer season. Note that the length of time during which data were collected varied between sites due to datalogger malfunction. Site 1 datalogger malfunctioned after day 178.

\section{$\downarrow$ ACKNOWLEDGEMENTS}

This material is based upon research supported by the National Science Foundation to D. Debinski under Grant No. 0518150. We would like to thank the University of Wyoming National Park Service Research Station and particularly Dr. Henry Harlow and Rich Viola for helping to set up this experiment. Janet Bala, Rick Williams and Karl Holte assisted with the plant identification.

\section{$\downarrow$ LiteratURE Cited}

Cross, M.S. and J. Harte. 2007. Compensatory responses to loss of warming-sensitive plant species. Ecology 80:740-748.

Despain, D.G. 1990. Yellowstone Vegetation: consequences of environment and history in a natural setting. Roberts Rinehart Publishers. Boulder, Colorado.

Dodd, M.B., W.K. Lauenroth and J.M. Welker. 1998. Differential water resource use by herbaceous and woody plant life-forms in a shortgrass steppe community. Oecologia 117:504-512

Ehleringer, J.R., S. Schwinning and R. Gebauer. 2000. Water use in arid land ecosystems. Pp. 347365 In: Physiological Plant Ecology. M.C. Press J.D. Scholes and M.G. Barker, (eds.).Blackwell science, Oxford UK.

Germino M.J. and W.K. Smith. 1999. Sky exposure, crown architecture, and low-temperature photoinhibition in conifer seedlings at alpine treeline. Plant, Cell, and Environment 22:407415.

Hill, J.P., M.J. Germino, J.M. Wraith, B.E. Olson and M.B. Swan. 2006. Advantages in water relations contribute to greater photosynthesis in Centaurea maculosa compared with established grasses. International Journal of Plant Sciences 167:269-277.

Inouye, R.S. 2006 Effect of shrub removal and nitrogen addition on soil moisture in sagebrush steppe. Journal of Arid Environments 65:604-618.

Knowles, N., M. Dettinger and D. Cayan. 2006. Trends in snowfall versus rainfall for the Western United States. Journal of Climate 19:45454559.

Mote, P.W., A. F. Hamlett, M.P. Clark and D. P. Lettenmaier. 2005. Declining mountain snowpack in western North America. American Meteorological Society. January:3949. 
Reiners, W.A., W.L. Baker, J.S. Baron et al. 2003. Natural Ecosystems 1. The Rocky Mountains. Pp. 145-184 In: Wagner, F. and T. Stohlgren. Preparing for a Changing climate: The potential consequences of climate variability and change. Rocky Mountain/Great Basin. A report of the Rocky Mountain/Great Basin Regional Assessment Team for the U.S. Global Change Research Program. Utah State Press. 240 pp.
Shaw, R.J. 1958. Vascular plants of Grand Teton National Park. American Midland Naturalist 59:146-166.

Walter, H. 1971. Natural Savannas: Ecology of Tropical and Sub-tropical vegetation. Oliver and Boyd. Edinburgh, Scotland.

Williams, D.G. and J.R. Ehleringer. 2000. Intra- and interspecific variation for summer precipitation use in pinyon-juniper woodlands. Ecological Monographs. 70:517-537. 